\title{
The EIMS fragmentation mechanisms of the sesquiterpenes corvol ethers A and B, epi-cubebol and isodauc-8-en-11-ol
}

\author{
Patrick Rabe and Jeroen S. Dickschat ${ }^{*}$
}

\author{
Full Research Paper \\ Address: \\ Kekulé-Institute of Organic Chemistry and Biochemistry, University of \\ Bonn, Gerhard-Domagk-Straße 1, 53121 Bonn, Germany \\ Email: \\ Jeroen S. Dickschat* - dickschat@uni-bonn.de \\ * Corresponding author \\ Keywords: \\ bacteria; isotopic labelling; mass spectrometry; reaction mechanisms; \\ terpenes
}

Beilstein J. Org. Chem. 2016, 12, 1380-1394.

doi:10.3762/bjoc. 12.132

Received: 20 May 2016

Accepted: 24 June 2016

Published: 05 July 2016

Associate Editor: J. A. Murphy

(ㄷ 2016 Rabe and Dickschat; licensee Beilstein-Institut.

License and terms: see end of document.

\begin{abstract}
Farnesyl diphosphate (FPP) and all fifteen positional isomers of $\left({ }^{13} \mathrm{C}_{1}\right) \mathrm{FPP}$ were enzymatically converted by the bacterial terpene cyclases corvol ether synthase from Kitasatospora setae, the epi-cubebol synthase from Streptosporangium roseum, and the isodauc-8-en-11-ol synthase from Streptomyces venezuelae. The enzyme products were analysed by GC-MS and GC-QTOF MS 2 and the obtained data were used to delineate the EIMS fragmentation mechanisms of the two sesquiterpene ethers corvol ethers A and $\mathrm{B}$, and the sesquiterpene alcohols epi-cubebol and isodauc-8-en-11-ol.
\end{abstract}

\section{Introduction}

Gas chromatography coupled to electron impact mass spectrometry (GC-EIMS) is a powerful and broadly applied method to investigate volatile natural products in complex mixtures [1]. Positive compound identification requires a good match of both the measured mass spectrum and retention time to the corresponding data obtained from an authentic standard. Furthermore, various high quality databases containing the EI mass spectra and retention indices of thousands of compounds are available that assist in automated compound identification [2,3]. If unknown compounds are detected in natural extracts, their structure elucidation by GC-MS is more difficult. The profound knowledge about EIMS fragmentation reactions can be used to identify certain structural motifs, e.g., the mass spectra of acyclic carbonyl compounds are often dominated by fragment ions formed via McLafferty rearrangement [4], while cyclohexene derivatives often show major fragment ions produced via retro-Diels-Alder reaction [5,6]. Such diagnostic fragment ions are of high value to delineate structural proposals for unknown analytes from their mass spectra, but for unambiguous proof of the suggested structures a synthesis of reference material is essential. Back in the 1960s, Ryhage and Stenhagen presented detailed studies on the EI mass spectra of deuterated and methyl-branched fatty acid methyl esters that revealed their fragmentation mechanisms [7,8]. Based on this work, we have recently identified various volatile fatty acid methyl esters (FAMEs) in headspace extracts of the actinobacterium 
Micromonospora aurantiaca [9] and more than 30 blastmycinones, a class of $\gamma$-lactones that depend on the antimycin biosynthetic gene cluster in several streptomycetes [10].

We have also recently developed structural proposals for a series of methylated monoterpenes from the 2-methylisoborneol biosynthetic pathway by comparing the mass spectra of the methylated compounds to their non-methylated analogs [11] Higher terpenes such as sesqui- and diterpenes, as being produced by terpene cyclases from oligoprenyl diphosphates, are usually (poly)cyclic compounds with different ring sizes, contain several methyl groups, and possibly one or more olefinic double bonds, an alcohol or ether function. Their much higher structural complexity compared to, e.g., FAMEs and monoterpenes renders a prediction of the fragmentation behaviour of unknown compounds in mass spectrometry and consequently the development of structural proposals from their mass spectra impossible. Only very few studies have addressed the fragmentation mechanisms of terpenes using isotopically labelled compounds [12-15], likely because the synthesis of the required labelled material is laborious and expensive. Furthermore, introduction of labelling into the various positions of the compound of interest may require a different synthetic strategy for each individual target isotopomer. Most of these studies made use of deuterium labellings that can frequently be introduced into reactive positions of a (functionalised) terpene isolated from the producing organism. Deuterium labellings also allow to follow hydrogen rearrangements, but non-specific hydrogen migrations during the fragmentation process and kinetic isotope effects can make data interpretation difficult. In contrast, the introduction of ${ }^{13} \mathrm{C}$-labelling into a terpene requires a de novo synthesis for each isotopomer, or at least a partial degradation of a terpene and reconstruction with a ${ }^{13} \mathrm{C}$ labelled building block. Alternatively, a ${ }^{13} \mathrm{C}$-labelled terpene may be obtained by feeding of labelled precursors to the producing organism, but this strategy will require high incorporation rates and usually delivers a mixture of various isotopomers. We have recently synthesised all fifteen isotopomers of $\left({ }^{13} \mathrm{C}_{1}\right)$ farnesyl diphosphate (FPP) that can be enzymatically converted with a sesquiterpene cyclase into the corresponding labelled sesquiterpene products [16]. These enzyme products carry a labelling $\left(>99 \%{ }^{13} \mathrm{C}\right)$ in specific positions that can easily be located, if the cyclisation mechanism of the terpene cyclase is known. Furthermore, ${ }^{13} \mathrm{C}$ NMR spectroscopy can be used to experimentally locate the labelling if the cyclisation mechanism is unidentified. As we have shown in two previous studies with $(1(10) E, 4 E, 6 S, 7 R)$-germacradien-6-ol synthase from Streptomyces pratensis and epi-isozizaene synthase from Streptomyces albus, that the enzymatically obtained products from the $\left({ }^{13} \mathrm{C}_{1}\right) \mathrm{FPP}$ isotopomers are useful for detailed investigations on the EIMS fragmentation mechanisms of sesquiterpenes [16,17].

In the present study we have used the same approach to investigate the fragmentation mechanisms for corvol ethers A and B, two sesquiterpene ethers with unique carbon skeletons that are made by a terpene cyclase from Kitasatospora setae [18], and the sesquiterpene alcohols epi-cubebol and isodauc-8-en-11-ol made by terpene cyclases from Streptosporangium roseum $[19,20]$ and from Streptomyces venezuelae [21].

\section{Results and Discussion}

To investigate the EIMS fragmentation mechanisms for the two sesquiterpene ethers corvol ether A (1) and corvol ether B (2), and for the sesquiterpene alcohols epi-cubebol (3) and isodauc8-en-11-ol (4) (Scheme 1), all fifteen positional isomers of $\left({ }^{13} \mathrm{C}_{1}\right)$ FPP [16] were enzymatically converted by the corvol ether synthase from K. setae KM-6054 [18], the epi-cubebol synthase from $S$. roseum DSM $43021[19,20]$, and the isodauc8-en-11-ol synthase from S. venezuelae ATCC 10712 [21], respectively. In previous work all used enzymes were mechanistically thoroughly studied, and therefore the locations of labellings in the obtained products are known [18-22]. The enzyme products were analysed via GC-MS, and for each of the ${ }^{13} \mathrm{C}$-labelled isotopomers of the investigated sesquiterpenes some of the fragment ions in their mass spectra clearly increased by $+1 \mathrm{amu}$, indicating that the corresponding carbon atom contributes to the fragment ion, while for other fragment ions no such increase was observed, showing that the respective labelled carbon is cleaved off during the formation. Furthermore, if multiple mechanisms lead to distinct fragment ions with the same nominal mass, representing different parts of the analyte, labelling of a carbon that does not belong to all these fragment ions will only lead to a partially increased $\mathrm{m} / \mathrm{z}$ peak by +1 amu in the mass spectrum. This is particularly true for the fragment ions in the low mass range that can be formed via multiple mechanisms, and thus these ions are not discussed

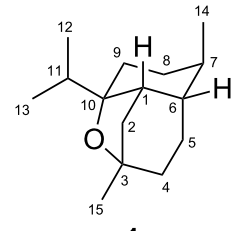

1

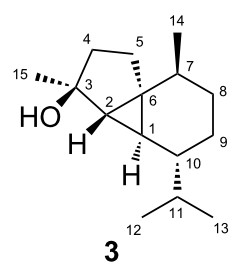

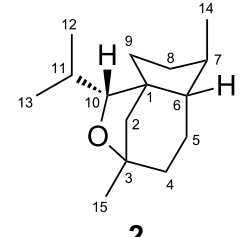

2

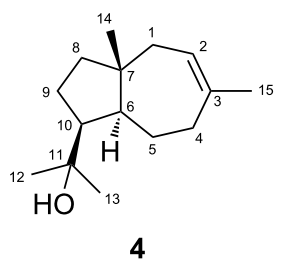

Scheme 1: Structures of corvol ethers A (1) and B (2), epi-cubebol (3), and isodauc-8-en-11-ol (4). Carbon numbering is not systematic, but is the same as for FPP, indicating the biosynthetic origin of each carbon by identical numbering. 
in detail here. For the full analysis of a certain fragment ion $\mathrm{m} / \mathrm{z}$ by comparison of all fifteen $\left({ }^{13} \mathrm{C}_{1}\right)$-isotopomers of a sesquiterpene to the non-labelled counterpart we have recently introduced the term 'position-specific mass shift analysis' for $\mathrm{m} / \mathrm{z}$ $\left(\mathrm{PMA}_{m / z}\right)$ [17].

\section{EIMS fragmentation of corvol ether $A$}

The EI mass spectra of unlabelled $\mathbf{1}$ and all fifteen positional isomers of $\left({ }^{13} \mathrm{C}_{1}\right)-\mathbf{1}$ are shown in Figure 1. The molecular ion $[\mathrm{M}]^{+}$, which is expected at $m / z=222$ for unlabelled $\mathbf{1}$, is not visible, suggesting a strong fragmentation of $\mathbf{1}$ upon electron impact ionisation. Besides the base peak at $m / z=179$, major fragment ions are detected at $m / z=161$ and $m / z=105$. The position-specific mass shift analysis for $m / z=179\left(\mathrm{PMA}_{179}\right)$ that summarises the extracted information from all the mass spectra in Figure 1 reveals a specific mechanism for the formation of the base beak ion with loss of the $\mathrm{C} 11-\mathrm{C} 12-\mathrm{C} 13$ portion of the molecule, while all other carbons contribute to this ion (marked in black, Scheme 2A). This is explainable by electron impact ionisation of $\mathbf{1}$ with loss of one electron from the oxygen lone pairs to $\mathbf{1}^{+\cdot}$, followed by $\alpha$-cleavage with loss of the isopropyl group to $\mathbf{A 1}^{+}$. This cation may ring-open to the cation $\mathbf{B 1}^{+}$. The $\mathrm{PMA}_{161}$ shows that the fragment ion $m / z=161$ is made up from the same part of the carbon backbone of $\mathbf{1}$ (Scheme 2B). Furthermore, the high resolution GC-QTOF $\mathrm{MS}^{2}$ analysis of $m / z=179$ reveals that the base peak ion is a direct precursor of $m / z=161$ by the loss of water (Figure S1, Supporting Information File 1). Starting from cation $\mathbf{A 1}^{+}$, a ring opening reaction with a proton transfer to the oxygen may yield $\mathrm{C1}^{+}$that upon hydrogen rearrangements via $\mathrm{D1}^{+}$to $\mathrm{E1}^{+}$and inductive cleavage of water results in the conjugated cation $\mathbf{F 1}^{+}$. Since the ${ }^{13} \mathrm{C}$-labelling experiments presented in this study cannot distinguish which of the hydrogens of $\mathbf{1}$ are rearranged or lost, alternative mechanisms may contribute to the formation of $m / z=161$, but such alternatives must end up in a fragment ion composed of the same carbon framework as for $\mathbf{F 1}^{+}$.

Due to the low abundance of the fragment ion at $\mathrm{m} / \mathrm{z}=135$ the $\mathrm{PMA}_{135}$ from the mass spectra in Figure 1 is not very conclusive, but seems to indicate a cleavage of the $\mathrm{C} 9-\mathrm{C} 10$ portion, besides the loss of $\mathrm{C} 11-\mathrm{C} 12-\mathrm{C} 13$ (Scheme 2C). $\mathrm{MS}^{2}$ analysis shows that this fragment ion arises from the base peak ion, but not from $m / z=161$ (Figures S1 and S2, Supporting Information File 1). The fragmentation of $\mathrm{C} 9-\mathrm{C} 10$ was confirmed by $\mathrm{MS}^{2}$ analysis of $m / z=180$ for all cases in which a ${ }^{13} \mathrm{C}$-labelling was present in $\mathrm{A1}^{+}$(Figure S3, Supporting Information File 1). Only for those isotopomers of $\mathbf{1}$ in which the ${ }^{13} \mathrm{C}$-labelling was located at $\mathrm{C} 9$ or $\mathrm{C} 10$ a fragment ion at $m / z=135$, but no significant ion at $\mathrm{m} / z=136$ was detected, while for all other isotopomers a peak at $\mathrm{m} / \mathrm{z}=136$ was observed (this method is abbreviated by $\mathrm{PMA}_{135(179)}$ ). The fragmentation of $\mathbf{A 1}^{+}$may proceed via cleavage of two bonds to $\mathbf{G 1}^{+}$, followed by loss of ketene via inductive cleavage and of two hydrogens by $\alpha$-cleavage to yield $\mathrm{H1}^{+}$. The formation of diradicals that may be highly transient species and are shown in brackets in Scheme 2, can be avoided by the assumption of a concerted process from $\mathrm{A1}^{+}$to $\mathrm{H1}^{+}$, but it will be very difficult, if not impossible, to distinguish experimentally between a stepwise and the alternative concerted mechanism.

Both $\mathrm{PMA}_{119}$ and $\mathrm{PMA}_{119(179)}$ point to a formation of the ion $m / z=119$ from the $\mathrm{C} 1-\mathrm{C} 6+\mathrm{C} 15$ portion of 1 (Scheme 2D). Furthermore, two of the carbons $\mathrm{C} 7-\mathrm{C} 10+\mathrm{C} 14$ participate in the formation of this fragment ion (carbons that only partially contribute to a fragment ion are marked in red in the PMAs), indicating that more than one fragmentation mechanism leading to fragment ions that represent different parts of $\mathbf{1}$ is active. Two inductive cleavages of $\mathbf{F} \mathbf{1}^{+}$with neutral loss of propene result in $\mathbf{I 1}^{+}$. Starting from $\mathbf{G 1}^{+}$, a similar reaction as described above for $\mathbf{H 1}^{+}(m / z=135)$ involves the neutral loss of ketene by inductive cleavage, and loss of one hydrogen and one methyl group by $\alpha$-cleavages to produce $\mathbf{J 1}^{+}(m / z=121)$. Finally, the loss of two more hydrogen atoms yields $\mathbf{K 1}^{+}$.

$\mathrm{PMA}_{105}$ suggests a generation of the fragment ion $\mathrm{m} / \mathrm{z}=105$ from C1-C6, C10 and C15 of 1 (Scheme 2E), while $\mathrm{MS}^{2}$ analysis confirms a strong formation of this fragment ion from $m / z=179$ and 161 (Figures S1 and S2, Supporting Information File 1). Accordingly, all $\mathrm{MS}^{2}$ analyses for $m / z=180$ of labelled 1 (Figure S3, Supporting Information File 1) indicate the origin of $m / z=105$ from the same part of the carbon skeleton, as

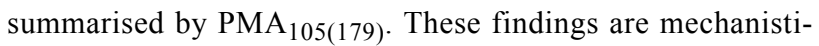
cally explainable by a hydrogen rearrangement from $\mathrm{Fi}^{+}$to $\mathrm{L1}^{+}$, followed by a ring opening with concomitant hydrogen rearrangement to $\mathrm{M1}^{+}$and $\alpha$-cleavage to $\mathrm{N1}^{+}$.

\section{EIMS fragmentation of corvol ether $B$}

The EI mass spectra of unlabelled $\mathbf{2}$ and of the fifteen enzymatically obtained isotopomers of $\left({ }^{13} \mathrm{C}_{1}\right)-2$ are depicted in Figure 2. As described above for $\mathbf{1}$, also for unlabelled $\mathbf{2}$ the molecular ion $[\mathrm{M}]^{+}$at $m / z=222$ was not detectable. Instead, the highest fragment ion is observed at $m / z=179$, the base peak ion is found at $m / z=135$, and other major fragment ions are at $m / z=161,150$ and 121. Similar to the situation for $1, \mathrm{PMA}_{179}$ reveals a formation of $m / z=179$ by loss of the isopropyl group C11-C12-C13 (Scheme 3A). This is explainable by electron impact ionisation of $\mathbf{2}$ with loss of an electron from an oxygen lone pair to $\mathbf{2}^{+\cdot}$ and subsequent $\alpha$-cleavage to $\mathbf{A} 2^{+}$that may stabilise by ring opening to $\mathbf{B 2}^{+}$. The $\mathrm{PMA}_{161}$ indicates that the fragment ion $m / z=161$ represents the same part of the carbon backbone of 2 as $m / z=179$ (Scheme 3B), while $\mathrm{MS}^{2}$ analysis of $m / z=179$ shows that this fragment ion is a precursor of 


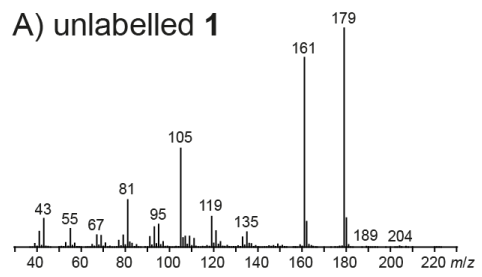

B) $\left(1-{ }^{13} \mathrm{C}\right)-1$

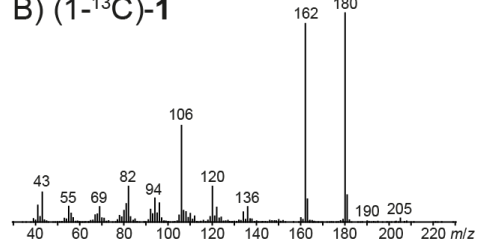

C) $\left(2-{ }^{13} \mathrm{C}\right)-1$

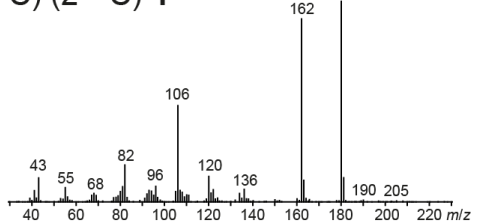

D) $\left(3-{ }^{13} \mathrm{C}\right)-1$
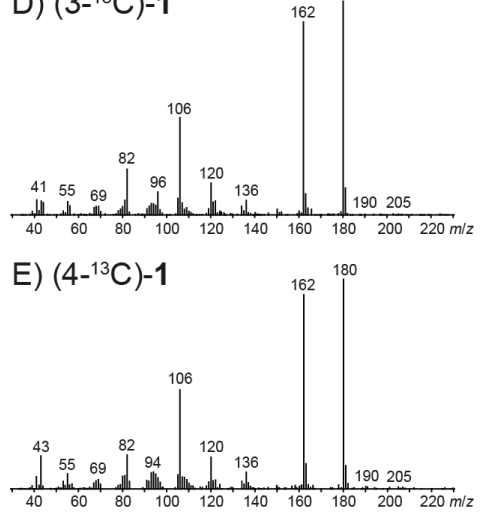

F) $\left(5-{ }^{13} \mathrm{C}\right)-1$

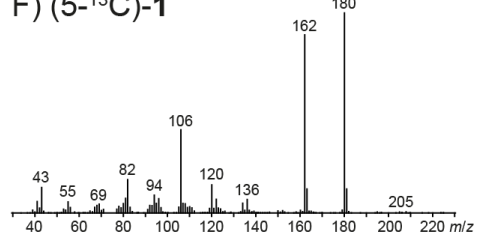

G) $\left(6-{ }^{13} \mathrm{C}\right)-1$

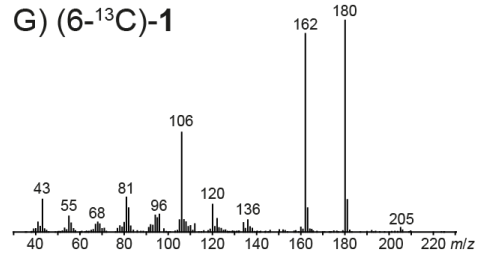

H) $\left(7-{ }^{13} \mathrm{C}\right)-1$

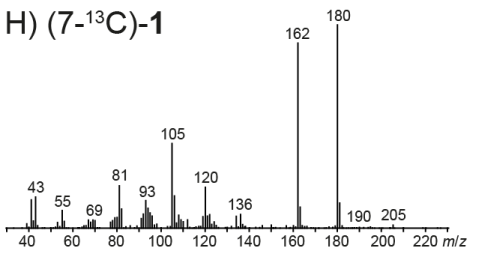

I) $\left(8-{ }^{13} \mathrm{C}\right)-1$
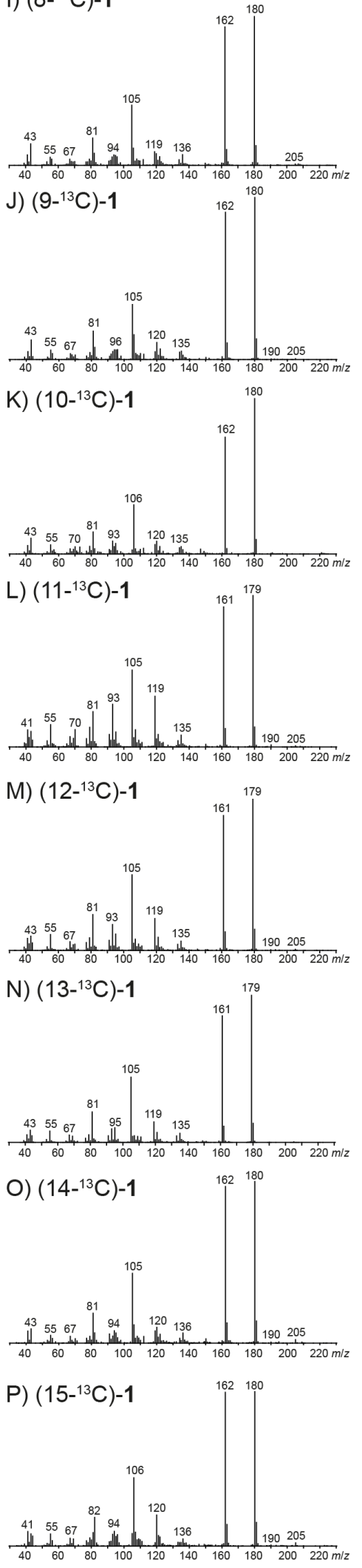

Figure 1: Mass spectra of unlabelled 1 and all fifteen positional isomers of $\left({ }^{13} C_{1}\right)-1$. 
A)

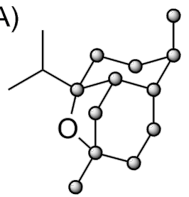

$\mathrm{PMA}_{179}$

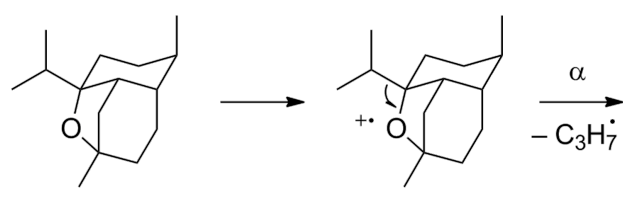

$1^{+\cdot}$

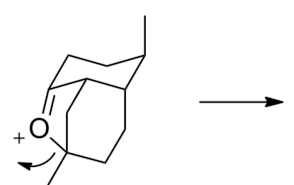

$\mathrm{A} 1^{+}$

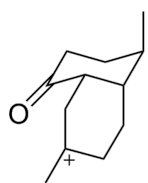

$\mathbf{B}^{+}(m / z=179)$

B)

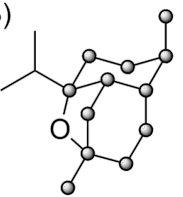

$\mathrm{PMA}_{161}$

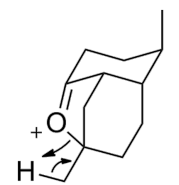

$\longrightarrow$ 等

$\mathrm{C}^{+}$<smiles>C=C1CC[C@H]2C(C)CC[C@@H](O)[C@@]2(C)C1</smiles>

D1 ${ }^{+}$<smiles>C=C1C=C2C(=O)CCC(C)[C@@H]2CC1</smiles>

$\mathrm{E} 1^{+}$<smiles>C=C1C=C2CCC[C@@H](C)[C@H]2CC1</smiles>

$\mathbf{F}^{+}(m / z=161)$

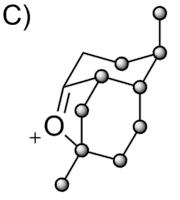

$\mathrm{PMA}_{135(179)}$

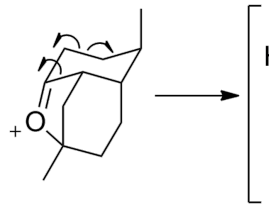

$\mathrm{A}^{+}$

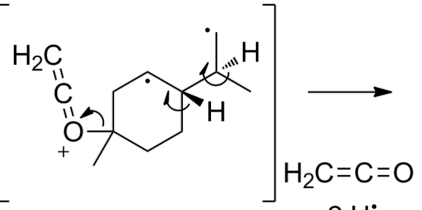

$\mathbf{G 1}^{+}(m / z=179)$

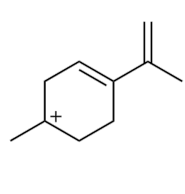

$\mathbf{H}^{+}(m / z=135)$

D)

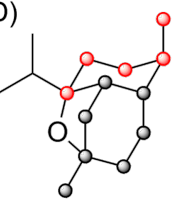<smiles>C=CC1=CC(=C)CC[CH+]1</smiles>

$\mathrm{PMA}_{119}$ $\mathbf{F 1}^{+}(m / z=161)$

$\mathbf{I} \mathbf{1}^{+}(\mathrm{m} / \mathrm{z}=119)$

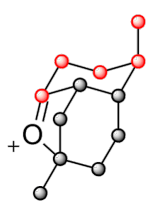

$\mathrm{PMA}_{119(179)}$

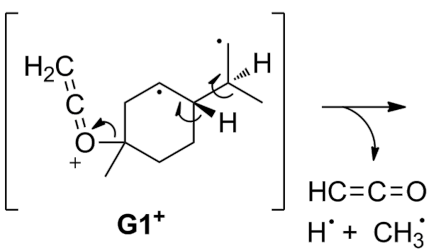<smiles>C=CC1=CC[C+](C)CC1</smiles><smiles>[Z][C]C(C)C(C)C</smiles>

$\mathbf{K}^{+}(m / z=119)$

E)

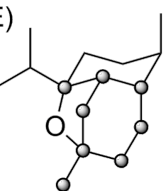

$\mathrm{PMA}_{105}$<smiles>C=C1C=C2[CH]CC[C@H](C)[C@H]2CC1</smiles>

$\mathbf{F 1}^{+}(m / z=161)$<smiles>C=C[C@@]12CCC(=C)C=C1CCC[C@H]2C</smiles>

$\mathrm{L}^{+}$

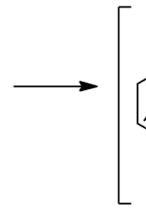

[<smiles>C=C1C=C([18F])C=CC1</smiles><smiles>CC1CC2OC3(O)OOC2(OOC3([O-])O)O1</smiles>

$\mathrm{PMA}_{105(179)}$ 


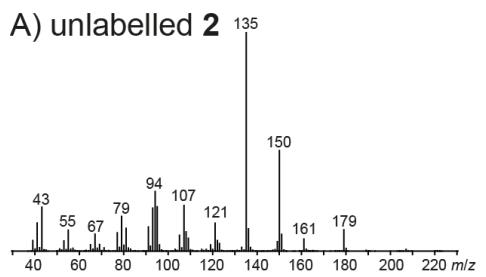

B) $\left(1-{ }^{13} \mathrm{C}\right)-2$

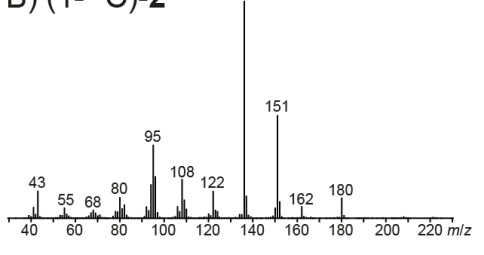

C) $\left(2-{ }^{13} \mathrm{C}\right)-2$

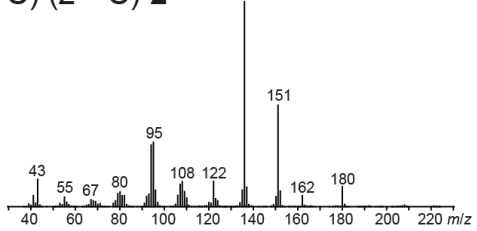

D) $\left(3-{ }^{13} \mathrm{C}\right)-2$

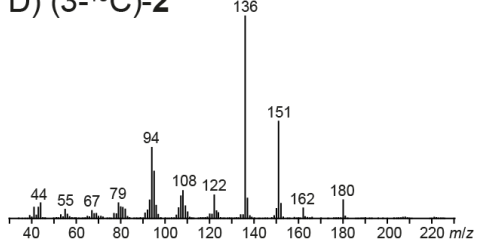

E) $\left(4-{ }^{13} \mathrm{C}\right)-2$

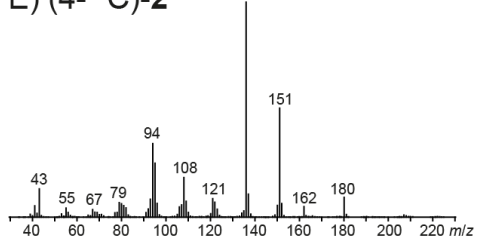

F) $\left(5-{ }^{13} \mathrm{C}\right)-2$
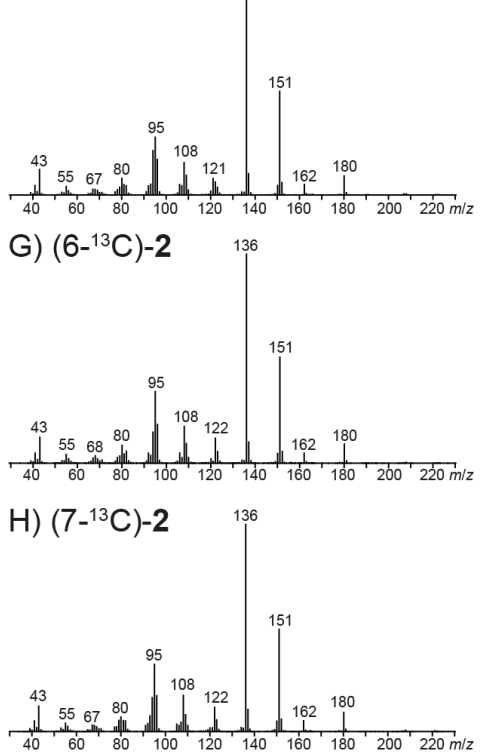

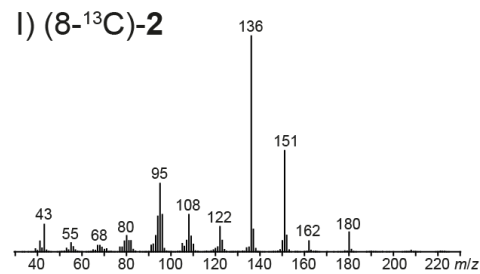

J) $\left(9-{ }^{13} \mathrm{C}\right)-2$
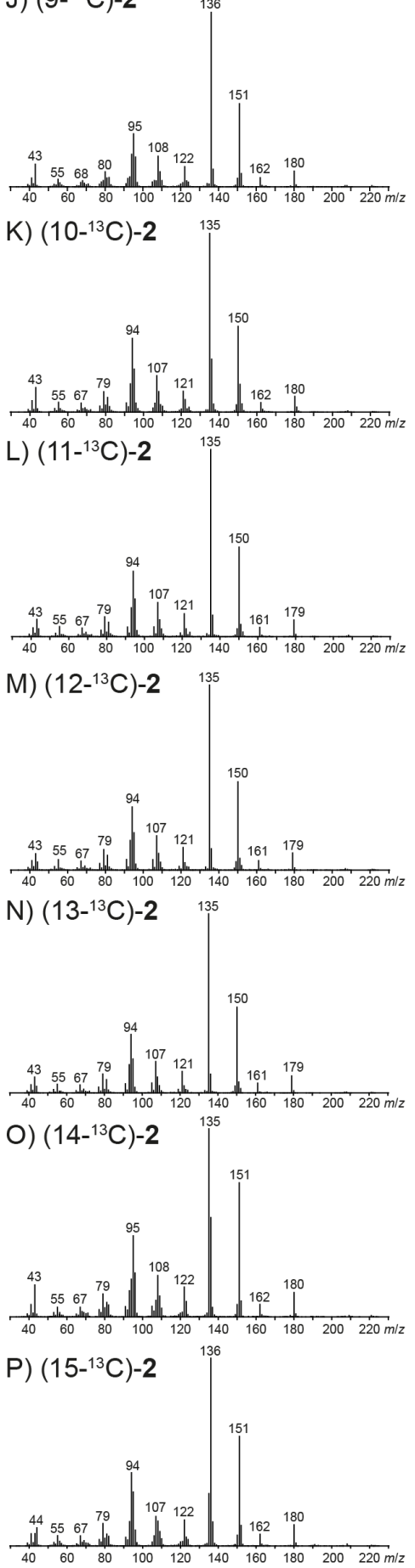

Figure 2: Mass spectra of unlabelled 2 and all fifteen positional isomers of $\left({ }^{13} C_{1}\right)-2$. 


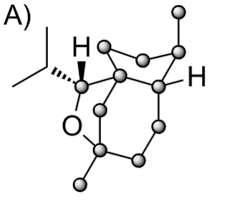

$\mathrm{PMA}_{179}$

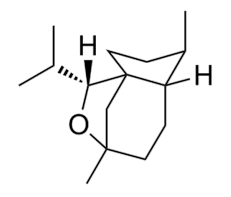

2

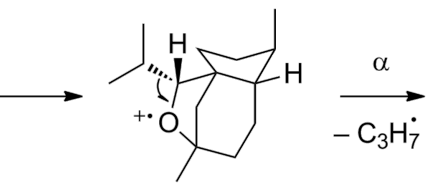

$2^{+\cdot}$

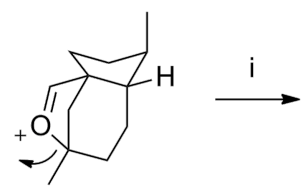

$\mathrm{A2}^{+}$

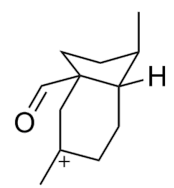

B2 $^{+}(m / z=179)$

B)

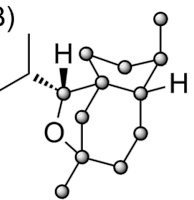

$\mathrm{PMA}_{161}$

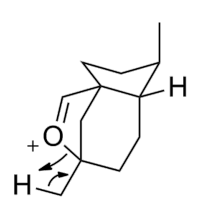

$\mathrm{A2}^{+}$<smiles>C=C1CCC2C(C)CC(C)C(C1)C2O</smiles>

$\mathrm{C2}^{+}$

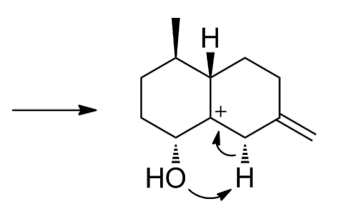

D2 $^{+}$

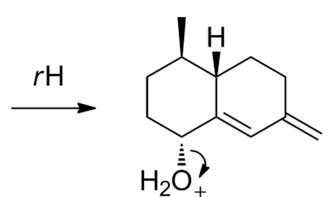

E2 $^{+}$<smiles>C=C1C=C2CCCC(C)[C@H]2CC1</smiles>

$\mathbf{F}^{+}(m / z=161)$

C)

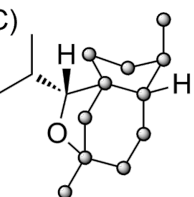

$\mathrm{PMA}_{150}$

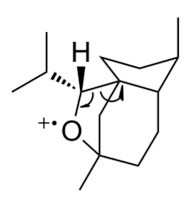

$2^{+\cdot}$

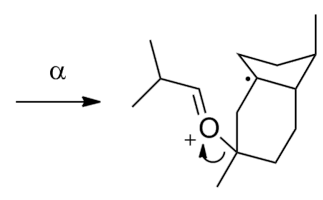

$\mathbf{G}^{+\cdot}$<smiles>CC(C=O)CC(C)(C)C</smiles><smiles>CC1CC[C@H]2C(C)CCC2C1C</smiles>

$\mathrm{H}^{+{ }^{\bullet}}$<smiles>CC1CC[C@H]2C(C)CCC2C1</smiles>

$\mathrm{H}^{+{ }^{+}}$<smiles>CC1CC[C@H]2CCCC[C@H]2C1C</smiles>

$\mathbf{J}^{+\bullet}(m / z=150)$

$\mathbf{L}^{+}(m / z=135)$

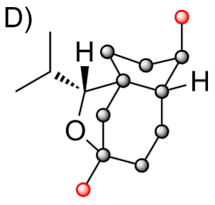

$\mathrm{PMA}_{135}$<smiles>CC1C=C2CCC(C)C2CCC1C</smiles>

$1 \mathbf{2}^{+\bullet}(m / z=150)$<smiles>CC1CC[C@H]2C(C)CCC2C1C</smiles>

$\mathbf{J 2}^{+\bullet}(m / z=150)$

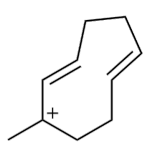

$\mathbf{K 2}^{+}(m / z=135)$<smiles>CC1CCC2C=CCCC12</smiles>

$\mathbf{M 2}^{+}(m / z=135)$

E)
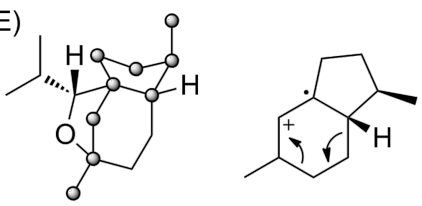

$\mathrm{PMA}_{121}$

$\mathbf{J 2}^{+\cdot}(m / z=150)$

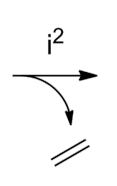<smiles>C/C=C/C1C=CC(C)C1</smiles><smiles>C[I-]</smiles><smiles>C/C=C/C1=CC(C)=CC1</smiles>

$\mathbf{N 2}^{+\bullet}(m / z=122)$

$\mathrm{O2}^{+}(\mathrm{m} / \mathrm{z}=121)$ 
$m / z=161$ (Figure S4, Supporting Information File 1), requiring the neutral loss of water. The relevant fragmentation reaction may proceed by ring opening of $\mathbf{A} \mathbf{2}^{+}$to $\mathbf{C} \mathbf{2}^{+}$followed by a ring expansion to $\mathbf{D 2} 2^{+}$, a proton transfer to $\mathbf{E 2} 2^{+}$and loss of water to $\mathbf{F 2}^{+}$. The fragment ion $\mathbf{F 2}^{+}$is structurally the same as $\mathbf{F 1}^{+}$suggested above for $m / z=161$ of $\mathbf{1}$. This structural identity of $\mathbf{F 1} \mathbf{1}^{+}$ and $\mathbf{F 2}^{+}$is also reflected by the highly similar $\mathrm{MS}^{2}$ spectra of $m / z=161$ for the corvol ethers A and B (Figures S2 and S5, Supporting Information File 1).

The $\mathrm{PMA}_{150}$ indicates a clear formation of $\mathrm{m} / \mathrm{z}=150$ from 2 with loss of the $\mathrm{C} 10-\mathrm{C} 13$ moiety (Scheme $3 \mathrm{C}$ ). A possible mechanism leading to this fragment ion starts from $\mathbf{2}^{+\cdot}$ that may undergo an $\alpha$-fragmentation to $\mathbf{G 2}^{+\cdot}$, followed by an inductive cleavage with neutral loss of isobutyraldehyde to $\mathbf{H 2}^{+}$. This reactive intermediate can stabilise to the conjugated radical cations $\mathbf{I}^{+\cdot}$ or $\mathbf{J 2}^{+\cdot}$ by two alternative hydrogen rearrangements.

$\mathrm{PMA}_{135}$ for the base peak ion $\mathrm{m} / z=135$ reveals that this fragment ion is produced from $\mathrm{C} 1-\mathrm{C} 9$ plus either $\mathrm{C} 14$ or $\mathrm{C} 15$ (Scheme 3D). In addition, $\mathrm{MS}^{2}$ analysis of $\mathrm{m} / \mathrm{z}=150$ identifies this fragment ion as a direct precursor for $m / z=135$ by loss of one of the methyl groups C14 or C15 (Figure S6, Supporting Information File 1). Plausible mechanisms include two consecutive or sequential $\alpha$-fragmentations from $\mathbf{I} 2^{+\cdot}$ with loss of C14 to $\mathbf{K 2}^{+}$. Alternatively, two $\alpha$-fragmentations from $\mathbf{J 2}^{+\cdot}$ may yield $\mathbf{L 2}^{+}$that is structurally different from $\mathbf{K 2}^{+}$, but represents the same part of the carbon skeleton of $\mathbf{2}$ (a similar reaction is also possible from $\mathbf{H 2}^{+}$). The less pronounced loss of $\mathrm{C} 15$ is explainable by simple $\alpha$-fragmentation of $\mathbf{J 2}^{+\cdot}$ that results in the allyl cation $\mathbf{M 2}^{+}$.

$\mathrm{PMA}_{121}$ (Scheme 3E) points to a formation of the fragment ion at $m / z=121$ by loss of $\mathrm{C} 4-\mathrm{C} 5$ and $\mathrm{C} 10-\mathrm{C} 13$ of 2 , but cleavage of the $\mathrm{C} 4-\mathrm{C} 5$ portion is less clear than that of $\mathrm{C} 10-\mathrm{C} 13$, because the fragment ion $m / z=122$ has a significantly increased intensity in the mass spectra of $\left(4-{ }^{13} \mathrm{C}\right)-2$ and $\left(5-{ }^{13} \mathrm{C}\right)-2$ in comparison to the mass spectrum of unlabelled 2 (Figure 2). However, $\mathrm{MS}^{2}$ analysis of $\mathrm{m} / \mathrm{z}=150$ shows that this fragment ion is a direct precursor of $m / z=121$. Taken together, these data indicate that loss of $\mathrm{C} 4-\mathrm{C} 5$ from a fragment ion $\mathrm{m} / \mathrm{z}=150$ is important for the formation of $m / z=121$, but possibly not the only relevant process. A possible mechanism for the fragmentation to $m / z=121$ starts from $\mathbf{J 2}^{+\cdot}$ by two inductive or $\alpha$-cleavages with neutral loss of ethene to $\mathbf{N 2}^{+\cdot}$ and subsequent cleavage of a hydrogen, e.g., to $\mathbf{O 2}^{+}$or a similar conjugated cation.

\section{EIMS fragmentation of epi-cubebol}

The mass spectra of $\mathbf{3}$ and the fifteen corresponding isotopomers of $\left({ }^{13} C_{1}\right)-3$ are shown in Figure 3. For the unla- belled compound a small, but clearly visible molecular ion is detected at $m / z=222$. The base peak is recorded at $m / z=207$ and other important fragment ions are observed at $m / z=179$, 161, 119 and 43. As revealed by $\mathrm{PMA}_{207}$, the base peak ion in the mass spectrum of $\mathbf{3}$ is only formed by loss of the methyl group $\mathrm{C} 15$, while cleavages of any of the other methyl groups do not contribute to its formation (Scheme 4A). This is easily understood by electron impact ionisation of $\mathbf{3}$ at the hydroxy function to $\mathbf{3 a}^{+\cdot}$, followed by $\alpha$-cleavage of $\mathrm{C} 15$. $\mathrm{PMA}_{179}$ indicates a formation of the fragment ion $\mathrm{m} / \mathrm{z}=179$ by loss of the isopropyl group C11-C12-C13 of $\mathbf{3}$ (Scheme 4B). Usually in sesquiterpene alcohols the electron impact ionisation proceeds with loss of an electron from one of the oxygen lone pairs, but in the special case of epi-cubebol that contains a 3-membered ring the ionisation step may also proceed with removal of an electron from the energetically high molecular orbitals of the cyclopropane moiety, resulting in $\mathbf{3 b}^{+\bullet}$. Neutral loss of the isopropyl group is then possible by $\alpha$-cleavage to $\mathbf{B 3}^{+}$. $\mathrm{PMA}_{161}$ shows that the fragment ion $m / z=161$ represents the same part of the carbon skeleton of 3 as $m / z=179$ (Scheme 4C), requiring the elimination of water that is plausible starting from $3 \mathbf{b}^{+\cdot}$ by a hydrogen rearrangement to $\mathbf{C 3}^{+\cdot}$, neutral loss of water by inductive cleavage to $\mathbf{D 3}^{+\cdot}$ and $\alpha$-cleavage to $\mathbf{E 3}^{+}$. The reverse order of steps for the losses of the isopropyl group and water is also possible, but $\mathrm{MS}^{2}$ analyses of $m / z=204$ and $m / z=179$ show that this alternative mechanism is much less pronounced (Figures S7 and S8, Supporting Information File 1).

For PMA $_{119}$ there is not in all fifteen labelling experiments a clear indication, whether or not the respective carbon contributes to the fragment ion $m / z=119$, but the most important mechanism for its formation involves the loss of the C8-C13 fragment of $\mathbf{3}$ (Scheme 4D). This is explainable by ionisation of 3 to $\mathbf{3 c}^{+\cdot}$, followed by $\alpha$-cleavage to $\mathbf{F 3}^{+\cdot}$. Two subsequent hydrogen rearrangements result in the conjugated reactive intermediates $\mathbf{G 3}^{+\cdot}$ and $\mathbf{H 3}^{+\cdot}$, which may be followed by the elimination of water to $\mathbf{I 3}^{+\cdot}$ that upon $\alpha$-cleavage yields the benzyl cation $\mathbf{J 3}^{+}$. Finally, $\mathrm{PMA}_{43}$ reveals a clean formation of the fragment ion $m / z=43$ from $\mathrm{C} 3$ and $\mathrm{C} 15$ (Scheme 4E). As shown by HRMS analysis, this fragment ion contains oxygen (measured: 43.0183, calculated for $\left[\mathrm{C}_{2} \mathrm{H}_{3} \mathrm{O}\right]^{+}:$43.0179). The radical cation $\mathbf{3 a}^{+\cdot}$ can undergo two sequential or consecutive $\alpha$-fragmentations to $\mathbf{K 3}^{+\cdot}$. A subsequent hydrogen rearrangement to $\mathbf{L 3}^{+\cdot}$ and two more $\alpha$-cleavages yield the acetylium cation $\mathbf{M 3}^{+}$, ethene and an allyl radical.

\section{EIMS fragmentation of isodauc-8-en-11-ol}

The mass spectra of unlabelled 4 and its $\left({ }^{13} \mathrm{C}_{1}\right)$-isotopomers are presented in Figure 4. For the unlabelled compound a small, but visible molecular ion is detected at $m / z=222$. The base peak is observed at $m / z=59$ and other important fragment ions are 
A) unlabelled 3

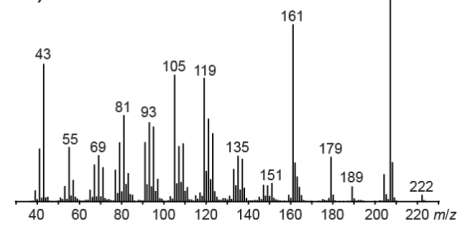

B) $\left(1-{ }^{13} \mathrm{C}\right)-3$

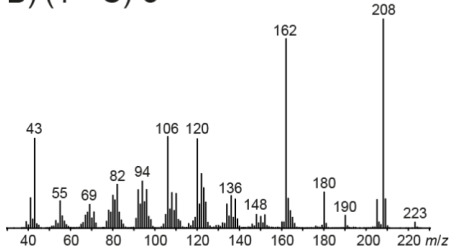

C) $\left(2-{ }^{13} \mathrm{C}\right)-3$

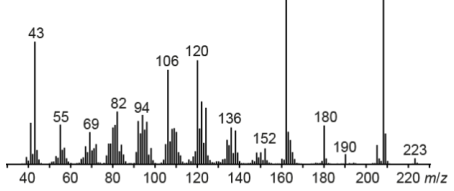

D) $\left(3-{ }^{13} \mathrm{C}\right)-3$

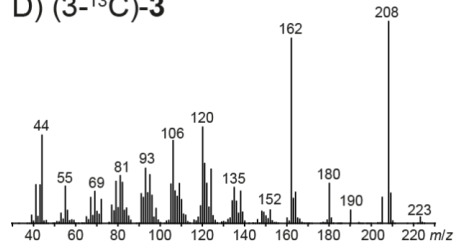

E) $\left(4-{ }^{13} \mathrm{C}\right)-3$

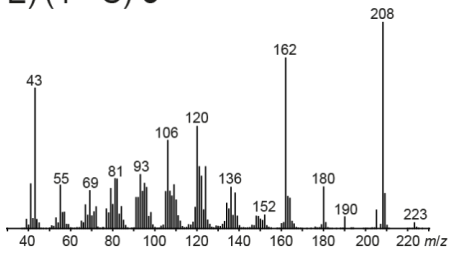

F) $\left(5-{ }^{13} \mathrm{C}\right)-3$

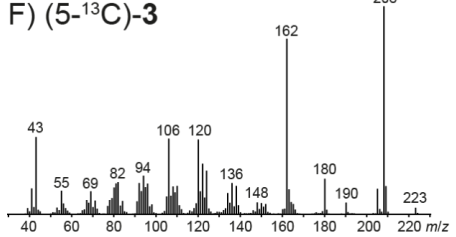

G) $\left(6-{ }^{13} \mathrm{C}\right)-3$

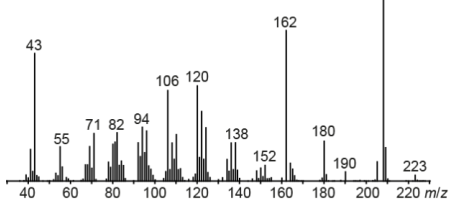

H) $\left(7-{ }^{13} \mathrm{C}\right)-3$

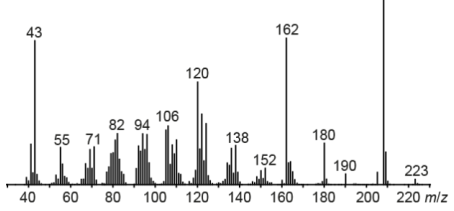

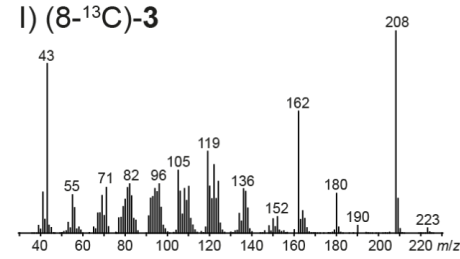

J) $\left(9-{ }^{13} \mathrm{C}\right)-3$
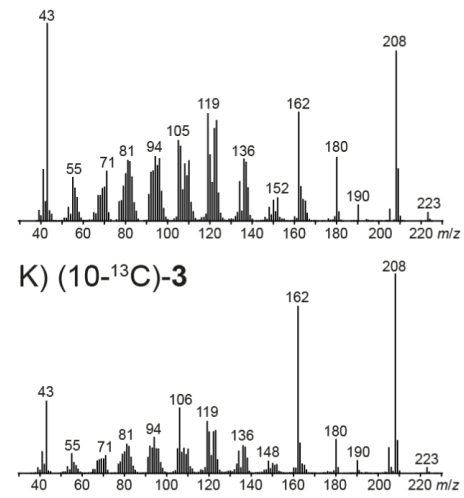

L) $\left(11-{ }^{13} \mathrm{C}\right)-3$

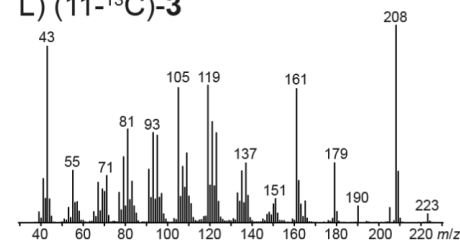

M) $\left(12-{ }^{13} \mathrm{C}\right)-3$
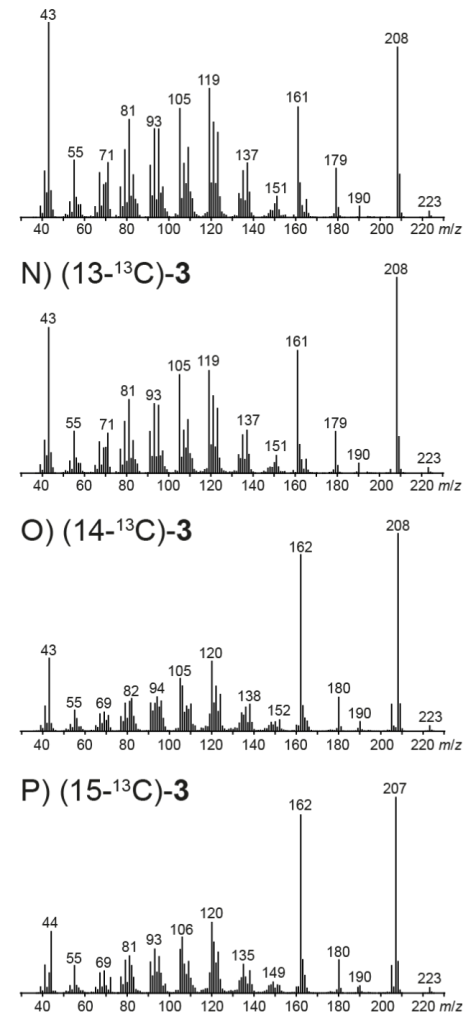

Figure 3: Mass spectra of unlabelled 3 and all fifteen positional isomers of $\left({ }^{13} C_{1}\right)-3$. 
A)

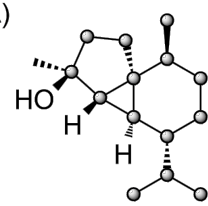

$\mathrm{PMA}_{207}$<smiles>CC(C)[C@H]1CC[C@@H](C)[C@@]23CC[C@](C)(O)[C@H]2[C@]13C</smiles>

3

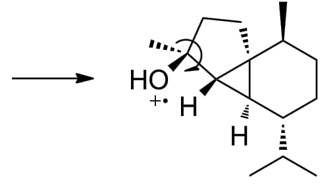

$3 a^{+\cdot}$

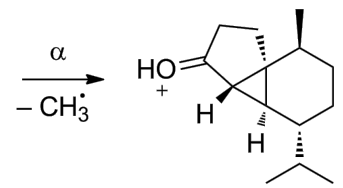

$\mathbf{A}^{+}(m / z=207)$

B)

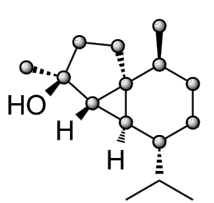

$\mathrm{PMA}_{179}$<smiles>CC(C)[C@H]1CC[C@@H](C)[C@@]23CC[C@](C)(O)[C@H]2[C@]13C</smiles>

3

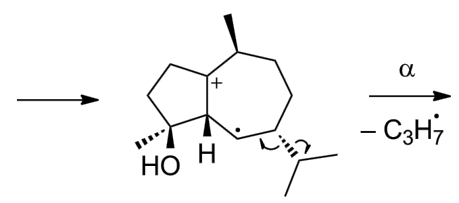

$3 b^{+*}$<smiles>CC1CCC=C[C@]23CCC[C@](C)(O)C2=C13</smiles>

$\mathrm{B}^{+}(m / z=179)$

C)

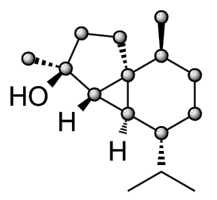

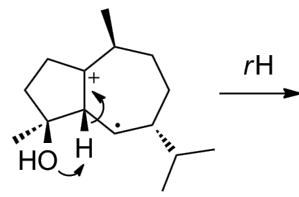

$3 b^{+\cdot}$<smiles>CC1CC[C@@H](C(C)C)CC2=C1CC[C@]2(C)O</smiles><smiles>CC1=C2CCC(C)C2=C(C(C)C)CCC1C</smiles><smiles>CC1=CCC2=C1C=CCC[C@H]2C</smiles>

$\mathrm{C3}^{+}$

$\mathbf{E}^{+}(m / z=161)$

D)

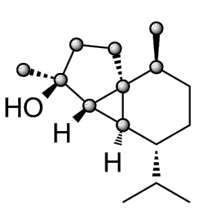

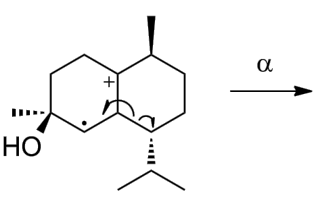<smiles>CC(C)CCCC(C)C1=CC=C[C@](C)(O)CC1</smiles><smiles>CC(C)CCCC(C)C1=CC=C(O)[C@](O)(CO)C1</smiles>

$\mathbf{G 3}^{+}$<smiles>CC(C)CCCC(C)C1C=CC(C)([18OH])C=C1</smiles>

$\mathrm{H}^{+*}$<smiles>CCCC(C)C</smiles>

$13^{+\cdot}$

$\mathrm{J3}^{+}(m / z=119)$

E)<smiles>CC(C)[C@H]1CC[C@@H](C)[C@@]23CCC(O)(O)[C@H]2[C@H]13</smiles>

$\mathrm{PMA}_{43}$

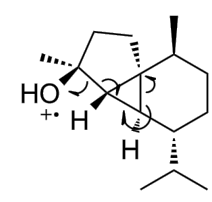

$3 \mathrm{a}^{+\cdot}$

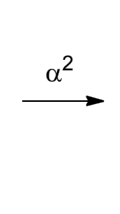

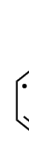

$\mathbf{M 3}^{+}(\mathrm{m} / \mathrm{z}=43)$<smiles>C=C[C@@H]1CC=C[C@@H](C(C)C)CC1</smiles><smiles>CC(=[OH+])CCC1C=C[C@@H](C(C)C)CCC1C</smiles>

$\mathrm{K}^{+*}$

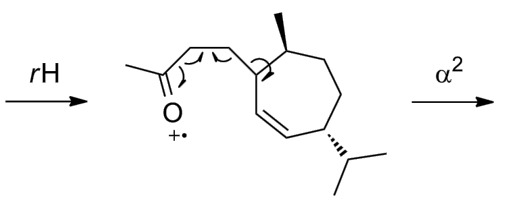

$\mathrm{L3}^{+\cdot}$ 

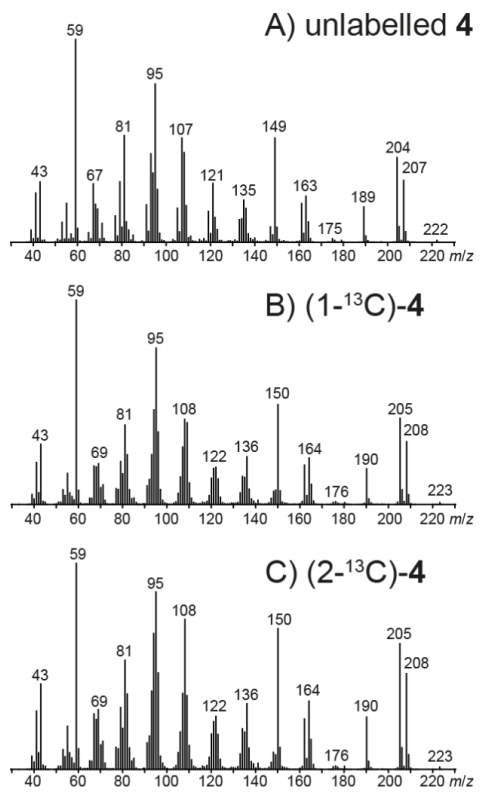

D) $\left(3-{ }^{13} \mathrm{C}\right)-4$
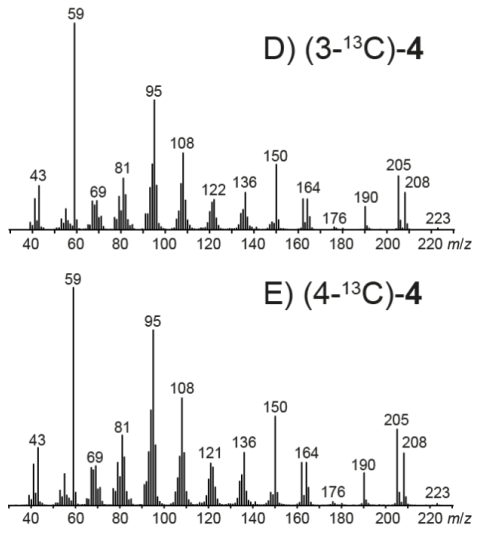

F) $\left(5-{ }^{13} \mathrm{C}\right)-4$
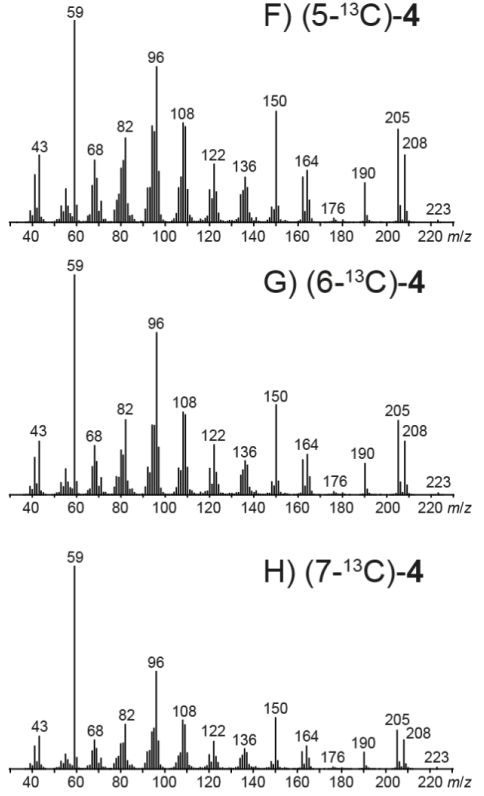
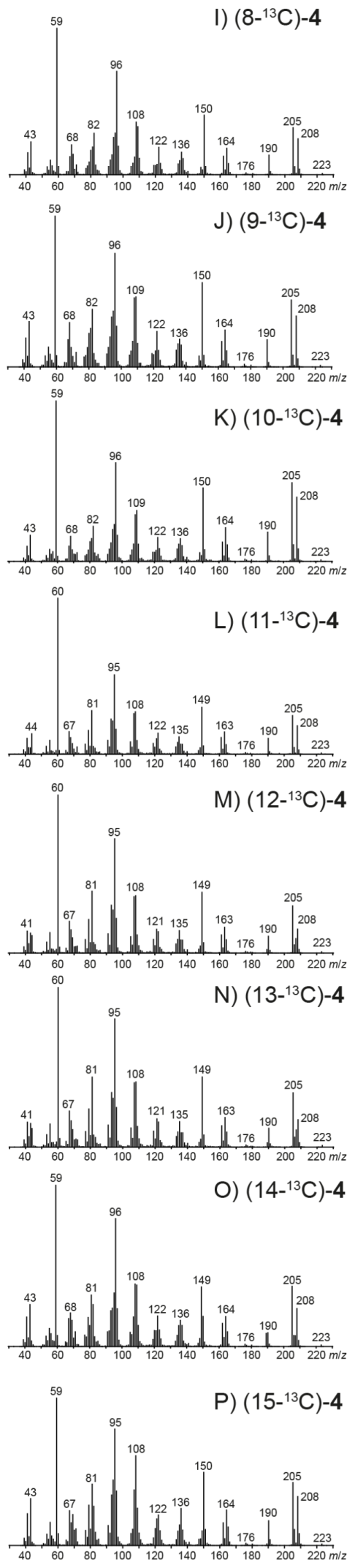
detected at $m / z=207,189,163,149$ and 95. The $\mathrm{PMA}_{207}$ shows that in contrast to the situation for $\mathbf{3}$ the fragment ion $m / z=207$ arises by cleavage of one of several methyl groups, i.e., either $\mathrm{C} 12, \mathrm{C} 13$ or $\mathrm{C} 14$ is lost (Scheme $5 \mathrm{~A}$ ). Electron impact ionisation at the oxygen lone pairs of 4 results in the radical cation $\mathbf{4 a}^{+\cdot}$ that can undergo one of two possible $\alpha$-cleavages with loss of $\mathrm{C} 12$ or $\mathrm{C} 13$ to yield $\mathbf{A 4}^{+}$. The alternative ionisation of $\mathbf{4}$ with loss of an electron from the olefinic double bond leads to $\mathbf{4} \mathbf{b}^{+\cdot}$ that may react by hydrogen rearrangement to $\mathbf{B 4}^{+\cdot}$ and $\alpha$-cleavage of $\mathrm{C} 14$ to $\mathbf{C 4}^{+}$. Interestingly, $\mathrm{PMA}_{189}$ demonstrates that the fragment ion $m / z=189$ is formed by loss of water and $\mathrm{C} 14$, while cleavage of $\mathrm{C} 12$ or $\mathrm{C} 13$ is prevented by the elimination of water (Scheme 5B). After ionisation to $\mathbf{4 a}^{\mathbf{+}^{+}}$, a hydrogen rearrangement results in $\mathrm{D4}^{+\cdot}$ which enables the loss of $\mathrm{C} 14$ by $\alpha$-cleavage to $\mathbf{E 4}^{+}$. A subsequent inductive cleavage with neutral loss of water yields $\mathbf{F 4}^{+}$. The last two steps of this mechanism may also proceed in reversed order. Both orders of steps are indeed active for this fragmentation mechanism, as indicated by $\mathrm{MS}^{2}$ analysis of $m / z=207$ and $m / z=204$ (Figures S9 and S10, Supporting Information File 1).

The $\mathrm{PMA}_{163}$ indicates a formation of $m / z=163$ by elimination of the C11-C12-C13 fragment including the alcohol function (Scheme 5C). The best explanation for this finding is a double $\alpha$-cleavage from $\mathbf{B 4}{ }^{+\cdot}$ directly to $\mathbf{G 4}^{+}$. The intensive fragement ion $m / z=149$ requires loss of the hydroxyisopropyl group plus $\mathrm{C} 14$, as summarised by $\mathrm{PMA}_{149}$ (Scheme 5D). Starting from $\mathrm{C4}^{+}$in which $\mathrm{C} 14$ is already missing, $\alpha$-cleavage of a hydrogen to the allyl radical $\mathbf{H}^{+\cdot}$ that induces a second $\alpha$-cleavage of the hydroxyisopropyl moiety results in $\mathbf{I 4}^{+}$.

Usually, the formation of fragment ions in the low $\mathrm{m} / \mathrm{z}$ region is not easily explained, because various multi-step processes lead to these ions. In contrast, $\mathrm{PMA}_{95}$ points to a surprisingly clear fragmentation mechanism, indicating that the fragment ion $m / z=95$ is made up from $\mathrm{C} 5-\mathrm{C} 10+\mathrm{C} 14$ of 4 (Scheme 5E). A plausible mechanism starts from $\mathbf{4 b}^{+\cdot}$ that results in $\mathbf{J 4}^{+\cdot}$ by inductive cleavage, followed by a neutral loss of isoprene to $\mathbf{K 4}^{+\bullet}$. The $\alpha$-cleavage of $\mathbf{J 4}^{+\cdot}$ would yield a primary radical, but this can immediately be stabilised if the $\alpha$-cleavage is coupled with a hydrogen rearrangement to generate the conjugated radical cation $\mathrm{K4}^{+\cdot}$. Another $\alpha$-cleavage of the hydroxyisopropyl group results in $\mathbf{L 4}^{+}$. Finally, the $\mathrm{PMA}_{59}$ demonstrates formation of this fragment ion from the hydroxyisopropyl group which is possible by a single $\alpha$-cleavage from $\mathbf{4 a}^{+\cdot}$ to $\mathbf{M 4}^{+}$ (Scheme 5F).

\section{Conclusion}

Isotopic labelling experiments continue to be a valuable source of information for many questions in natural product chemistry [23]. Many recent examples have shown how isotopic labelling experiments can unravel the complex and sometimes surprising cyclisation cascades that are catalysed by terpene cyclases in the conversion of simple linear substrates to polycyclic terpenes with usually several stereocentres [24-28]. We have demonstrated here, how isotopic labelling experiments can be used to investigate the EIMS fragmentation mechanisms of structurally complex sesquiterpenes. This field was initiated in the 1960s with main contributions by Djerassi, but since that time, not much knowledge has been added. One of the main problems is certainly the accessibility of isotopically labelled terpenes. We have solved this problem by our recent synthesis of all fifteen isotopomers of $\left({ }^{13} \mathrm{C}_{1}\right)$ FPP [16] that can now be used for enzymatic conversions into sesquiterpenes, which allows for various enzyme mechanistic experiments and, as we have shown here, for investigations on the EIMS fragmentation mechanisms. We will continue to report on other mechanistic problems of terpene chemistry by use of the $\left({ }^{13} \mathrm{C}_{1}\right)$ FPPs in due course.

\section{Experimental GC-MS and GC-QTOF MS analysis}

GC-MS analyses were performed using a 7890B gas chromatograph connected to a 5977A inert mass detector (Agilent). The GC was equipped with a HP5-MS fused silica capillary column ( $30 \mathrm{~m}, 0.25 \mathrm{~mm}$ i. d., $0.50 \mu \mathrm{m}$ film). The instrumental parameters of the GC were (1) inlet pressure: $77.1 \mathrm{kPa}, \mathrm{He}$ $23.3 \mathrm{~mL} \mathrm{~min}^{-1}$, (2) injection volume: $2 \mu \mathrm{L}$, (3) split mode (10:1 to $50: 1,60 \mathrm{~s}$ valve time), (4) carrier gas: $\mathrm{He} 1 \mathrm{~mL} \mathrm{~min}^{-1}$, (5) transfer line: $250^{\circ} \mathrm{C}$, and (6) electron energy: $70 \mathrm{eV}$. The temperature program of $\mathrm{GC}$ was set to: $5 \mathrm{~min}$ at $50{ }^{\circ} \mathrm{C}$, then increasing by $10^{\circ} \mathrm{C} \min ^{-1}$ to $320^{\circ} \mathrm{C}$, followed by 5 min at $320{ }^{\circ} \mathrm{C}$.

GC-HRMS analyses were carried out with a 7890B gas chromatograph connected to a 7200 accurate mass QTOF mass detector (Agilent) equipped with a HP5-MS fused silica capillary column $(30 \mathrm{~m}, 0.25 \mathrm{~mm}$ i. d., $0.50 \mu \mathrm{m}$ film). The instrumental parameters were (1) inlet pressure: $83.2 \mathrm{kPa}, \mathrm{He}$ $24.6 \mathrm{~mL} \mathrm{\text {min}^{-1 }}$, (2) injection volume: $2 \mu \mathrm{L}$, (3) split mode (10:1 to $50: 1,60 \mathrm{~s}$ valve time), (4) carrier gas: $\mathrm{He} 1 \mathrm{~mL} \mathrm{m^{-1 }}$, (5) transfer line: $250{ }^{\circ} \mathrm{C}$, (6) electron energy $70 \mathrm{eV}$, (7) collision cell gas flow: $1 \mathrm{~mL} \mathrm{~min}^{-1} \mathrm{~N}_{2}$, (8) collision energy: $15 \mathrm{~V}$, and (9) MS 1 scan resolution mode: narrow $(\mathrm{m} / \mathrm{z}+/-0.5)$. The temperature program of $\mathrm{GC}$ was set to: $5 \mathrm{~min}$ at $50{ }^{\circ} \mathrm{C}$, then increasing by $10^{\circ} \mathrm{C} \min ^{-1}$ to $320^{\circ} \mathrm{C}$, followed by $5 \mathrm{~min}$ at $320{ }^{\circ} \mathrm{C}$.

\section{Incubation experiments with labelled $\left({ }^{13} \mathrm{C}_{1}\right)$ FPPs}

E. coli $\mathrm{BL} 21$ was transformed with the appropriate expression plasmid for corvol ether synthase, epi-cubebol synthase or isodauc-8-en-11-ol synthase [18,19,21]. The transformants were 


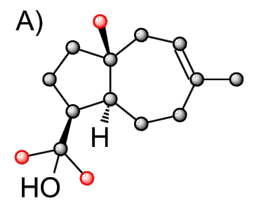

$\mathrm{PMA}_{207}$<smiles>CC1=CCC2(C)CCC(C(C)(C)O)C2CC1</smiles>

4

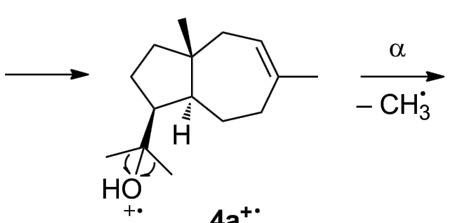

$+4 \mathrm{a}^{+}$<smiles>CC(=O)[C@H]1CCC2(C)CC=C(C)CC[C@H]12</smiles>

$\mathbf{A 4}^{+}(m / z=207)$

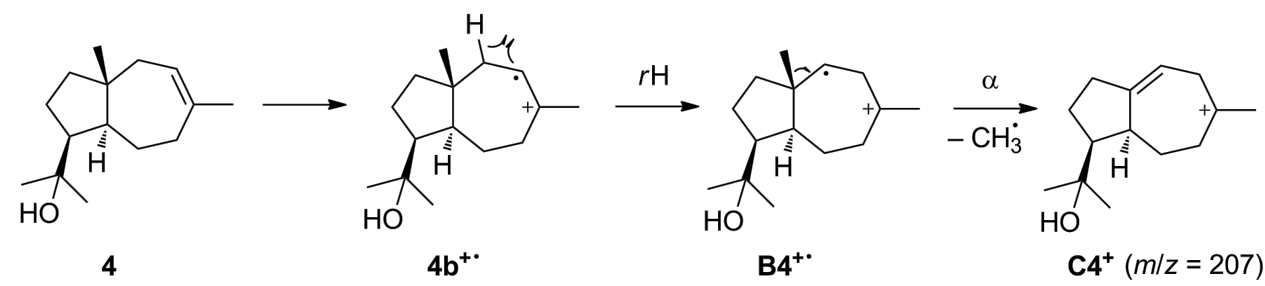

B)

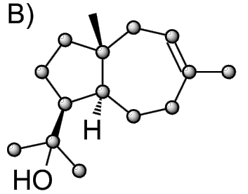

$\mathrm{PMA}_{189}$

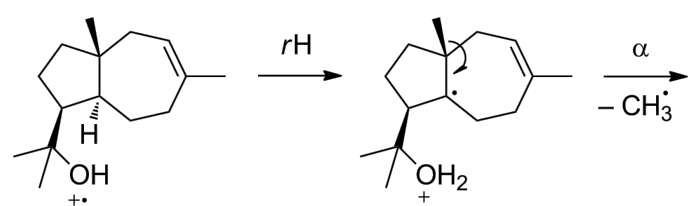

D4 $^{+\cdot}$

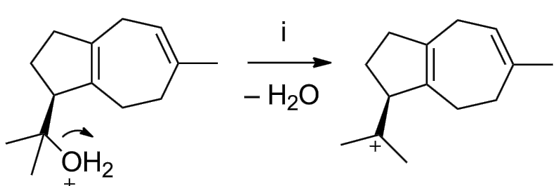

$\mathrm{E4}^{+}(\mathrm{m} / \mathrm{z}=207)$
$\mathbf{F 4}^{+}(m / z=189)$
C)

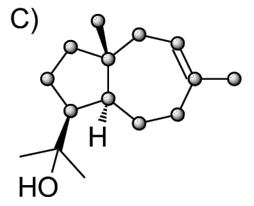

$\mathrm{PMA}_{163}$<smiles>CC1CCCC(C2C(C(C)(C)O)CCC2(C)C)CC1</smiles>

$\mathrm{B4}^{+\cdot}$

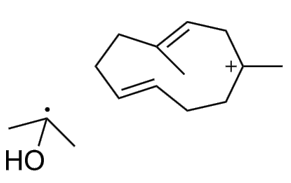

$\mathbf{G 4}^{+}(m / z=163)$
D)<smiles>COC12OC=C(O)COC1(C)OCC2C(C)(C)O</smiles>

$\mathrm{PMA}_{149}$<smiles>CC1CC=C2CCC(C(C)(O)O)C2CC1</smiles><smiles>C[I-]C1CCCCC1</smiles><smiles>CC1CC=C2CCC(C(C)(C)O)C2CC1</smiles>

$\mathrm{H}^{+}{ }^{+}$

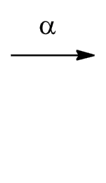

HO $14^{+}(m / z=149)$

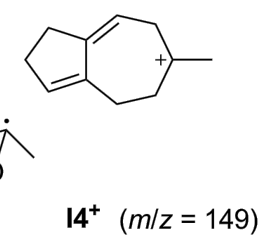

E)<smiles>CC1=CCC2(O)COC(C1O)C(C(C)(C)O)CO2</smiles>

$\mathrm{PMA}_{95}$<smiles>CC1CCC2CC1(C)CCC2C(C)(C)O</smiles>

$4 b^{+*}$

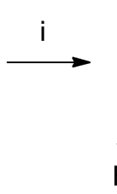<smiles>C=CC(=C)C(C)(C)C(C)(C)C</smiles>

$\mathrm{J4}^{+\cdot}$<smiles>CC1=C(C)C(C(C)(C)O)CCC1C(C)(C)O</smiles>

$\mathrm{K}^{+*}$
F)<smiles>CC1=CCC2(C)CCC(C(=O)O)C2CC1</smiles>

$\mathrm{PMA}_{59}$<smiles>CC1=CCC2(C)CCC(C)C2CC1C(C)O</smiles><smiles>CC(C)=O</smiles><smiles>CC1=CCC2(C)CCCC2CC1</smiles>

$\mathbf{M 4}^{+}(m / z=59)$

Scheme 5: PMAs and EIMS fragmentation mechanisms for the fragment ions A) $\mathrm{m} / \mathrm{z}=207, \mathrm{~B}) \mathrm{m} / \mathrm{z}=189, \mathrm{C}) \mathrm{m} / \mathrm{z}=163, \mathrm{D}) \mathrm{m} / \mathrm{z}=149, \mathrm{E}) \mathrm{m} / \mathrm{z}=95$ and F) $m / z=59$ of 4 . Black carbons contribute fully and red carbons contribute partially to the formation of a fragment ion. $\alpha$ : $\alpha$-cleavage, $r H$ : hydrogen rearrangement, i: inductive cleavage. 
used to inoculate a $20 \mathrm{~mL} 2 \mathrm{YT}$ liquid preculture (tryptone $16 \mathrm{~g}$, yeast extract $10 \mathrm{~g}, \mathrm{NaCl} 5 \mathrm{~g}$, water $1 \mathrm{~L}$ ) containing kanamycin $(50 \mathrm{mg} / \mathrm{L})$ that was grown overnight. The next morning the preculture was used to inoculate an expression culture (2YT, $1 \mathrm{~L})$ containing kanamycin $(50 \mathrm{mg} / \mathrm{L})$. The cells were grown to an $\mathrm{OD}_{600}=0.4$ at $37^{\circ} \mathrm{C}$ and $160 \mathrm{rpm}$. After cooling of the culture to $18{ }^{\circ} \mathrm{C}$ for 45 minutes, IPTG $(0.4 \mathrm{mM})$ was added. The culture was incubated at $18{ }^{\circ} \mathrm{C}$ and $160 \mathrm{rpm}$ overnight for protein expression. Harvesting of $E$. coli cells by centrifugation at $4{ }^{\circ} \mathrm{C}$ and $3600 \mathrm{rpm}$ for 45 minutes, resuspension in $20 \mathrm{~mL}$ binding buffer $\left(20 \mathrm{mM} \mathrm{Na}_{2} \mathrm{HPO}_{4}, 0.5 \mathrm{M} \mathrm{NaCl}, 20 \mathrm{mM}\right.$ imidazole, $1 \mathrm{mM} \mathrm{MgCl}_{2}, \mathrm{pH}$ 7.0) and cell disruption by ultra-sonication on ice for $4 \times 60 \mathrm{~s}$ followed by centrifugation at $4{ }^{\circ} \mathrm{C}$ and $11000 \mathrm{rpm}$, yielded in the soluble enzyme fraction. Protein purification was performed by $\mathrm{Ni}^{2+}$-NTA affinity chromatography with $\mathrm{Ni}^{2+}$-NTA superflow (Novagen) using binding buffer and elution buffer $\left(20 \mathrm{mM} \mathrm{Na}_{2} \mathrm{HPO}_{4}, 0.5 \mathrm{M} \mathrm{NaCl}, 0.5 \mathrm{M}\right.$ imidazole, $1 \mathrm{mM} \mathrm{MgCl}_{2}, \mathrm{pH}$ 7.0). Incubation experiments were performed with the pure protein fractions (checked by SDSPAGE) and all fifteen isotopomers of farnesyl diphosphate. Incubation experiments were carried out using $1 \mathrm{~mL}$ of the enzyme fraction and $1 \mathrm{~mL}$ of a solution of the isotopomer of $\left({ }^{13} \mathrm{C}_{1}\right)$ FPP $\left(0.2 \mathrm{mg} / \mathrm{mL}\right.$ in $\left.\mathrm{H}_{2} \mathrm{O}\right)$ for $3 \mathrm{~h}$ at $28^{\circ} \mathrm{C}$. The reaction mixtures were extracted with $n$-hexane $(300 \mu \mathrm{L})$ and analyzed by GC-MS and GC-QTOF MS.

\section{Supporting Information}

\section{Supporting Information File 1 \\ HRMS spectra. \\ [http://www.beilstein-journals.org/bjoc/content/ supplementary/1860-5397-12-132-S1.pdf]}

\section{Acknowledgements}

This work was funded by the DFG (DI1536/7-1).

\section{References}

1. Dickschat, J. S. Nat. Prod. Rep. 2014, 31, 838-861. doi:10.1039/c3np70080a

2. Mass Spectra. In NIST Chemistry WebBook; Linstrom, P. J.; Mallard, W. G., Eds.; National Institute of Standards and Technology: Gaithersburg, USA, 2016.

3. Adams, R. P. Identification of Essential Oil Components by Gas Chromatography/Mass Spectrometry; Allured Publishing Corporation: Carol Stream, IL, USA, 2009.

4. McLafferty, F. W. Anal. Chem. 1959, 31, 82-87. doi:10.1021/ac60145a015

5. Biemann, K. Angew. Chem., Int. Ed. Engl. 1962, 1, 98-111. doi:10.1002/anie.196200981

6. Budzikiewicz, H.; Brauman, J. I.; Djerassi, C. Tetrahedron 1965, 21 , 1855-1879. doi:10.1016/S0040-4020(01)98656-9

7. Ryhage, R.; Stenhagen, E. Ark. Kemi 1960, 15, 291-315.
8. Dinh-Nguyen, N.; Ryhage, R.; Stallberg-Stenhagen, S.; Stenhagen, E. Ark. Kemi 1961, 18, 393-399.

9. Dickschat, J. S.; Bruns, H.; Riclea, R. Beilstein J. Org. Chem. 2011, 7, 1697-1712. doi:10.3762/bjoc.7.200

10. Riclea, R.; Aigle, B.; Leblond, P.; Schoenian, I.; Spiteller, D.; Dickschat, J. S. ChemBioChem 2012, 13, 1635-1644. doi:10.1002/cbic. 201200260

11. Brock, N. L.; Ravella, S. R.; Schulz, S.; Dickschat, J. S. Angew. Chem., Int. Ed. 2013, 52, 2100-2104. doi:10.1002/anie.201209173

12. Weinberg, D. S.; Djerassi, C. J. Org. Chem. 1966, 31, 115-119. doi:10.1021/jo01339a024

13. Karliner, J.; Djerassi, C. J. Org. Chem. 1966, 31, 1945-1956. doi:10.1021/jo01344a063

14. Tsai, L.; Highet, R. J.; Herz, W. J. Org. Chem. 1969, 34, 945-948. doi:10.1021/jo01256a035

15. Muccino, R. R.; Djerassi, C. J. Am. Chem. Soc. 1973, 95, 8726-8733. doi:10.1021/ja00807a037

16. Rabe, P.; Barra, L.; Rinkel, J.; Riclea, R.; Citron, C. A.; Klapschinski, T. A.; Janusko, A. Angew. Chem., Int. Ed. 2015, 54, 13448-13451. doi:10.1002/anie.201507615

17. Rabe, P.; Klapschinski, T. A.; Dickschat, J. S. ChemBioChem 2016. doi:10.1002/cbic.201600237

18. Rabe, P.; Pahirulzaman, K. A. K.; Dickschat, J. S. Angew. Chem., Int. Ed. 2015, 54, 6041-6045. doi:10.1002/anie.201501119

19. Dickschat, J. S.; Pahirulzaman, K. A. K.; Rabe, P.; Klapschinski, T. ChemBioChem 2014, 15, 810-814. doi:10.1002/cbic.201300763

20. Rabe, P.; Schmitz, T.; Dickschat, J. S. Beilstein J. Org. Chem. 2016, submitted.

21. Rabe, P.; Rinkel, J.; Klapschinski, T. A.; Barra, L.; Dickschat, J. S. Org. Biomol. Chem. 2016, 14, 158-164. doi:10.1039/C5OB01998B

22. Rabe, P.; Janusko, A.; Goldfuss, B.; Dickschat, J. S. ChemBioChem 2016, 17, 146-149. doi:10.1002/cbic.201500543

23. Rinkel, J.; Dickschat, J. S. Beilstein J. Org. Chem. 2015, 11, 2493-2508. doi:10.3762/bjoc.11.271

24. Meguro, A.; Motoyoshi, Y.; Teramoto, K.; Ueda, S.; Totsuka, Y.; Ando, Y.; Tomita, T.; Kim, S.-Y.; Kimura, T.; Igarashi, M.; Sawa, R.; Shinada, T.; Nishiyama, M.; Kuzuyama, T. Angew. Chem., Int. Ed. 2015, 54, 4353-4356. doi:10.1002/anie.201411923

25. Ye, Y.; Minami, A.; Mandi, A.; Liu, C.; Taniguchi, T.; Kuzuyama, T.; Monde, K.; Gomi, K.; Oikawa, H. J. Am. Chem. Soc. 2015, 137, 11846-11853. doi:10.1021/jacs.5b08319

26. Matsuda, Y.; Mitsuhashi, T.; Lee, S.; Hoshino, M.; Mori, T.; Okada, M.; Zhang, H.; Hayashi, F.; Fujita, M.; Abe, I. Angew. Chem., Int. Ed. 2016, 55, 5785-5788. doi:10.1002/anie.201601448

27. Qin, B.; Matsuda, Y.; Mori, T.; Okada, M.; Quan, Z.; Mitsuhashi, T.; Wakimoto, T.; Abe, I. Angew. Chem., Int. Ed. 2016, 55, 1658-1661. doi:10.1002/anie.201509263

28. Burkhardt, I.; Siemon, T.; Henrot, M.; Studt, L.; Rösler, S.; Tudzynski, B.; Christmann, M.; Dickschat, J. S. Angew. Chem., Int. Ed. 2016. doi:10.1002/anie.201603782 


\section{License and Terms}

This is an Open Access article under the terms of the Creative Commons Attribution License

(http://creativecommons.org/licenses/by/2.0), which permits unrestricted use, distribution, and reproduction in any medium, provided the original work is properly cited.

The license is subject to the Beilstein Journal of Organic Chemistry terms and conditions:

(http://www.beilstein-journals.org/bjoc)

The definitive version of this article is the electronic one which can be found at:

doi:10.3762/bjoc.12.132 